\title{
Autour du paon et du phénix. Étude d'une iconographie cultuelle et funéraire dans le Bassin méditerranéen ( $\mathrm{IV}^{\mathrm{e}}$-XII ${ }^{\mathrm{e}}$ siècles)
}

Thèse de doctorat en histoire de l'art médiéval, sous la direction de Daniel Russo, université de Bourgogne Franche-Comté, soutenue le 18 novembre 2017

\section{Raphaël Demès}

\section{(2) OpenEdition}

1 Journals

Édition électronique

URL : https://journals.openedition.org/cem/15911

DOI : $10.4000 /$ cem. 15911

ISSN : 1954-3093

Éditeur

Centre d'études médiévales Saint-Germain d'Auxerre

Référence électronique

Raphaël Demès, « Autour du paon et du phénix. Étude d'une iconographie cultuelle et funéraire dans le Bassin méditerranéen ( $v^{\mathrm{e}}$-x॥$\|^{\mathrm{e}}$ siècles) », Bulletin du centre d'études médiévales d'Auxerre | BUCEMA [En ligne], 22.2 | 2018, mis en ligne le 23 janvier 2019, consulté le 22 septembre 2022. URL : http:// journals.openedition.org/cem/15911; DOI : https://doi.org/10.4000/cem.15911

Ce document a été généré automatiquement le 22 septembre 2022.

\section{c)}

Creative Commons - Attribution - Pas d'Utilisation Commerciale - Partage dans les Mêmes Conditions 4.0 International - CC BY-NC-SA 4.0

https://creativecommons.org/licenses/by-nc-sa/4.0/ 


\section{Autour du paon et du phénix. Étude d'une iconographie cultuelle et funéraire dans le Bassin méditerranéen ( $\mathrm{IV}^{\mathrm{e}}-\mathrm{XII}{ }^{\mathrm{e}}$ siècles)}

Thèse de doctorat en histoire de l'art médiéval, sous la direction de Daniel Russo, université de Bourgogne Franche-Comté, soutenue le 18 novembre 2017

\section{Raphaël Demès}

«En faisant la roue, cet oiseau, dont le pennage traîne à terre, apparaît encore plus beau, mais se découvre le derrière ${ }^{1}$. " En caractérisant avec humour le paon dans son Bestiaire ou Cortège d'Orphée (1911), Guillaume Apollinaire (1880-1918) met en évidence un point essentiel de l'image du paon, tel qu'il est interprété de nos jours. S'il est le plus souvent associé à l'orgueil, à la vanité et à la superficialité,

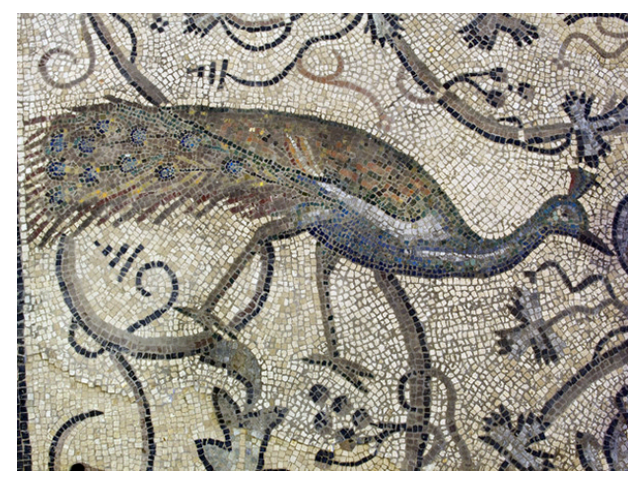
la signification de cet oiseau était tout autre au Moyen Âge. Avant le XII siècle, l'oiseau était attaché au thème de la renaissance, un processus également inscrit au cœur du mythe du phénix. Ce dernier, unique représentant de son espèce, est lié aujourd'hui encore à la cyclicité, à la régénération par le feu et à la résurrection. Il réapparaît régulièrement dans l'art et la littérature sous la forme d'un rapace aux plumes flamboyantes, bien que cette image soit assez rare dans l'iconographie antique et médiévale. Nous avons ainsi choisi de mettre en regard l'iconographie du paon et du phénix et d'étudier l'évolution de leur signification respective, afin de mettre en lumière les liens étroits tissés entre ces deux oiseaux. 
2 Des points de contact entre le paon et le phénix ont d'abord été mis en évidence au cours de nos recherches de master portant sur quelques aspects de l'iconographie du paon à Rome, Ravenne et dans l'espace italo-lombard entre le IV et le XII ${ }^{e}$ siècle $^{2}$. Si la première borne chronologique permet d'insister sur une période charnière et de mettre en relief le processus de christianisation du paon et du phénix, la seconde correspond à un moment de basculement de sens pour le paon et à un certain déclin du nombre d'occurrences de ces deux oiseaux. De fait, le paon et le phénix apparaissent côte à côte dès le $\mathrm{I}^{\mathrm{er}}$ siècle à Pompéi ${ }^{3}$ et au sein de plusieurs lieux de culte chrétiens à partir $\mathrm{du} \mathrm{v}^{\mathrm{e}}$ siècle. Aucune étude n'avait pourtant été menée sur les raisons et les circonstances de leur rapprochement, autant visuel que sémantique. L'horizon d'étude de notre thèse correspond à l'ensemble du Bassin méditerranéen, un espace permettant l'observation de la circulation et de la diffusion des images, des schémas et des objets empreints du paon et du phénix. Leur figuration quasi continue entre le $\mathrm{IV}^{\mathrm{e}}$ et le $\mathrm{XII}^{\mathrm{e}}$ siècle nous a conduit à réfléchir sur la transmission, les réappropriations et les relectures de la signification de ces oiseaux christianisés au $\mathrm{IV}^{\mathrm{e}}$ siècle. La thèse, dont nous exposerons ici les grandes lignes, porte sur le développement parallèle de l'iconographie du paon et de celle du mythique phénix dans des contextes cultuels et funéraires dans le Bassin méditerranéen entre le $\mathrm{IV}^{\mathrm{e}}$ et le $\mathrm{XII}^{\mathrm{e}}$ siècle ${ }^{4}$. La méthode adoptée s'appuie, d'une part, sur le croisement d'informations issues de ressources textuelles et visuelles sur chacun de ces deux oiseaux qui ont nourri un véritable imaginaire depuis l'Antiquité. D'autre part, notre approche relève de l'histoire de l'art tout en tenant compte des apports d'autres domaines liés aux sciences humaines et sociales, de l'histoire, de l'archéologie, de l'histoire des textes ou bien encore de l'anthropologie sociale, comme autant de points d'entrée dans le document placé à la base de nos réflexions ${ }^{5}$.

3 L'étude de la naissance et des renaissances des figures du paon et du phénix est au cœur de notre thèse, tel un parcours marqué de plusieurs étapes. La première partie commence par une double mise au point historiographique concernant ces deux oiseaux. Le propos se poursuit avec une présentation détaillée du corpus documentaire et de la base de données, dont l'analyse donne corps à la deuxième et à la troisième parties. Cette première partie s'interroge également sur les prémices littéraires et iconographiques du paon et du phénix au cours des premiers siècles avant notre ère. Les ensembles documentaires réunis par Roelof van den Broek (1931- $)^{6}$ pour le phénix et par Helmut Lother ${ }^{7}$ (1898-1970) pour le paon ont constitué la base de notre corpus largement étoffé au cours de nos recherches doctorales. Nos réflexions se sont appuyées sur un corpus de 570 documents, soit 490 documents dans lesquels apparaissent un ou plusieurs paons couvrant une période allant du v siècle av. J.-C. au $\mathrm{XIII}^{\mathrm{e}}$ siècle (fig. 1) et un espace réunissant 245 cités réparties dans 24 pays actuels (fig. 2, 3 et 4 ). 
Fig. 1 - Profil chronologique des figurations du paon et du phénix ( $\mathrm{V}^{\mathrm{e}}$ siècle av. J.-C.-XIII ${ }^{\mathrm{e}}$ siècle)

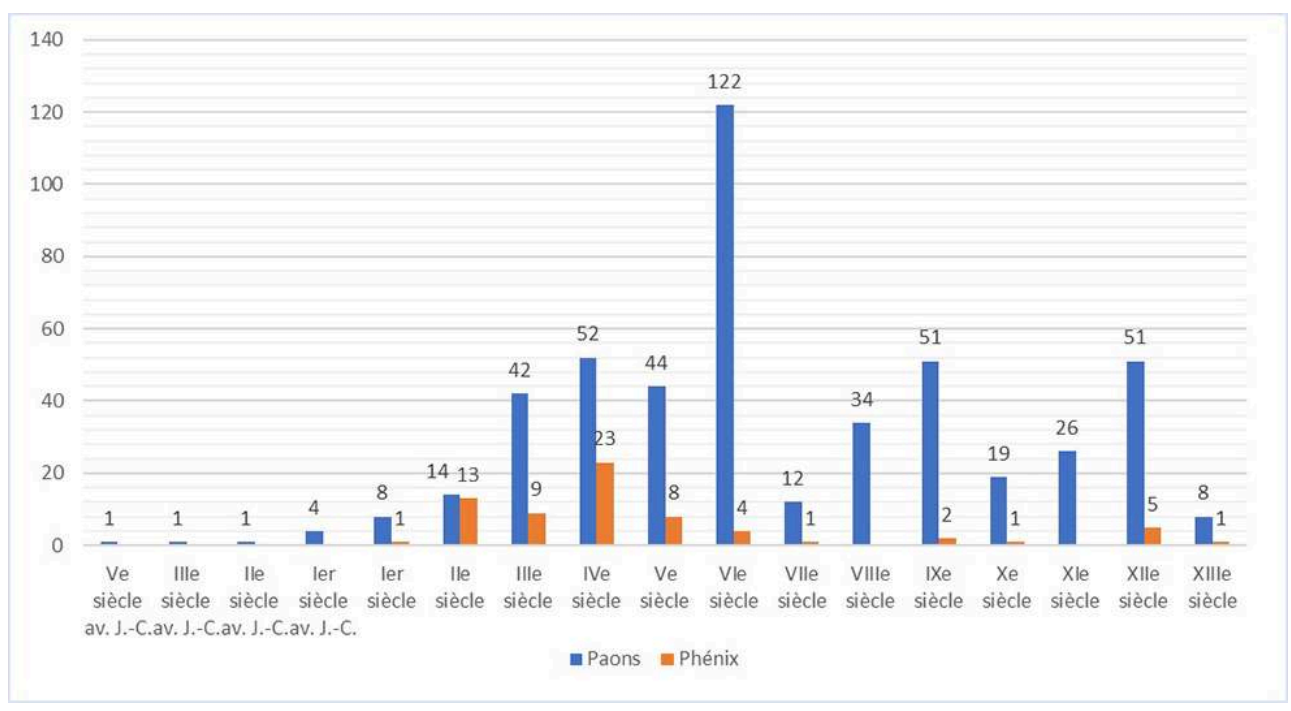

Fig. 2 - Répartition géographique globale des cités associées à chaque type de document (paons, phénix, benu, créatures hybrides) entre le $\|^{\mathrm{e}}$ millénaire av. J.-C. et le XIII ${ }^{\mathrm{e}}$ siècle

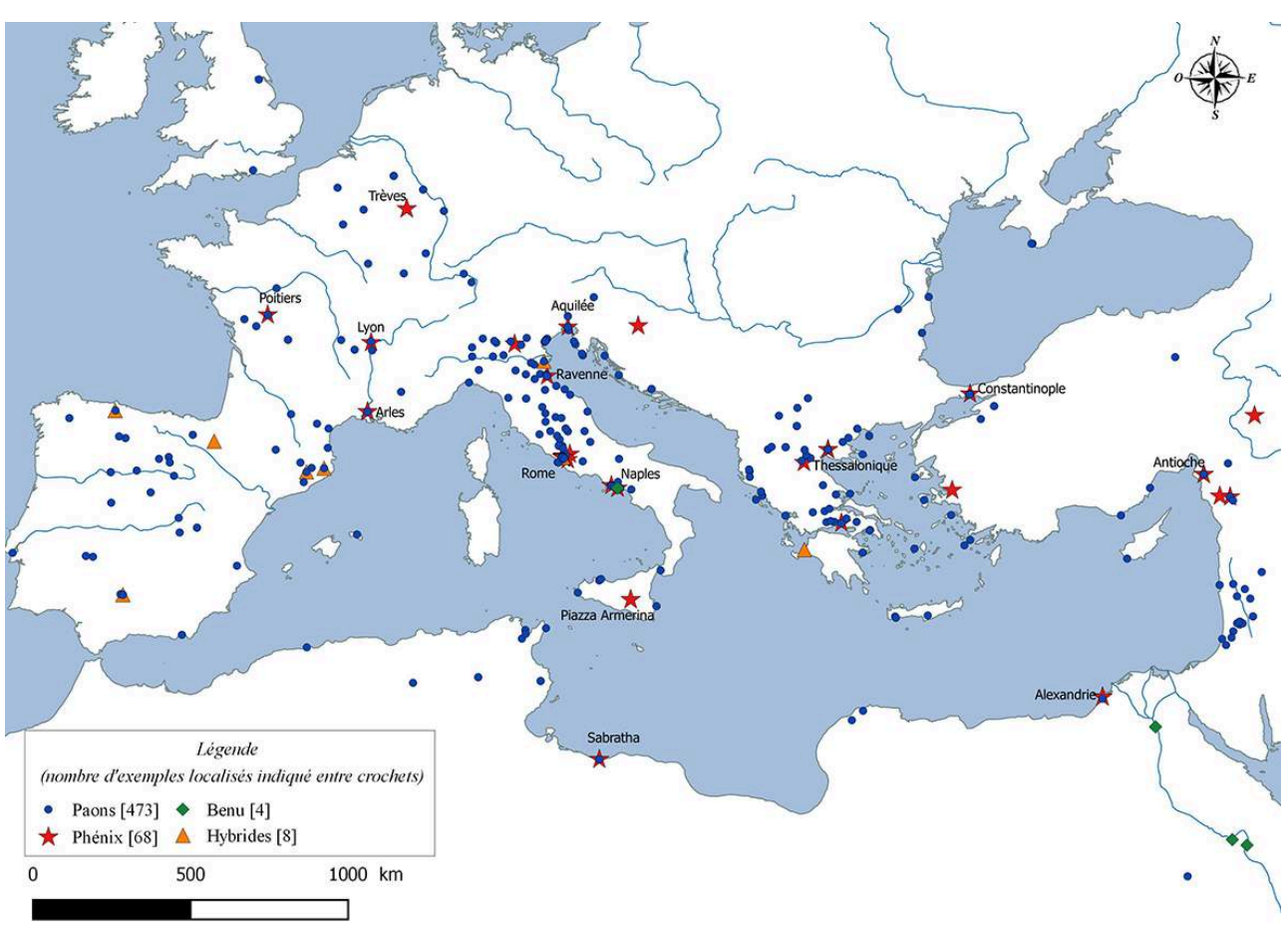


Fig. 3 - Répartition géographique des cités concernées par la figuration du paon (II ${ }^{\mathrm{e}}$ siècle av. J.-C.XIII' siècle)

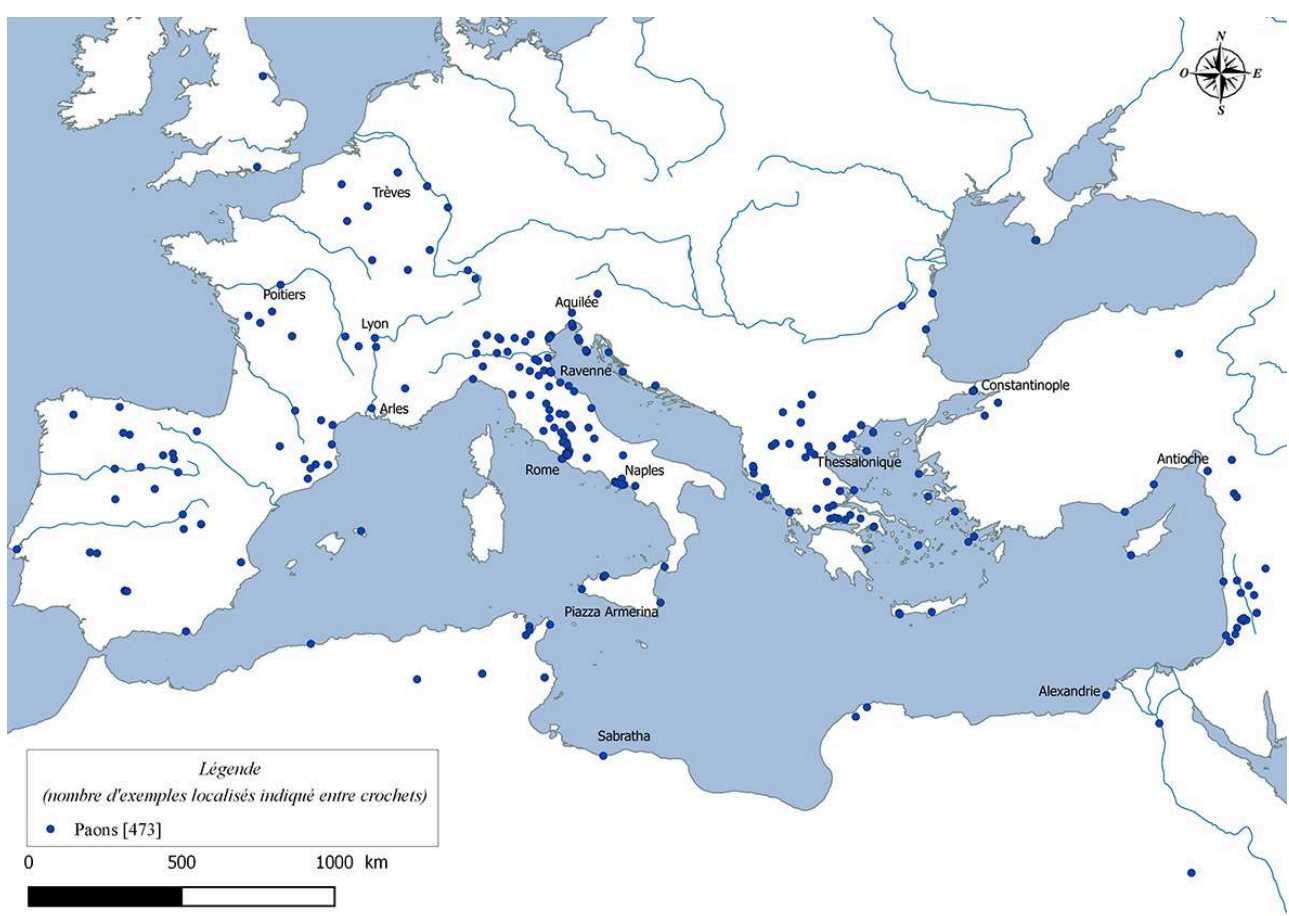

Fig. 4 - Répartition et densité des figurations du paon par cité concernée entre le ॥e millénaire av. J.-C. et le XIII" siècle

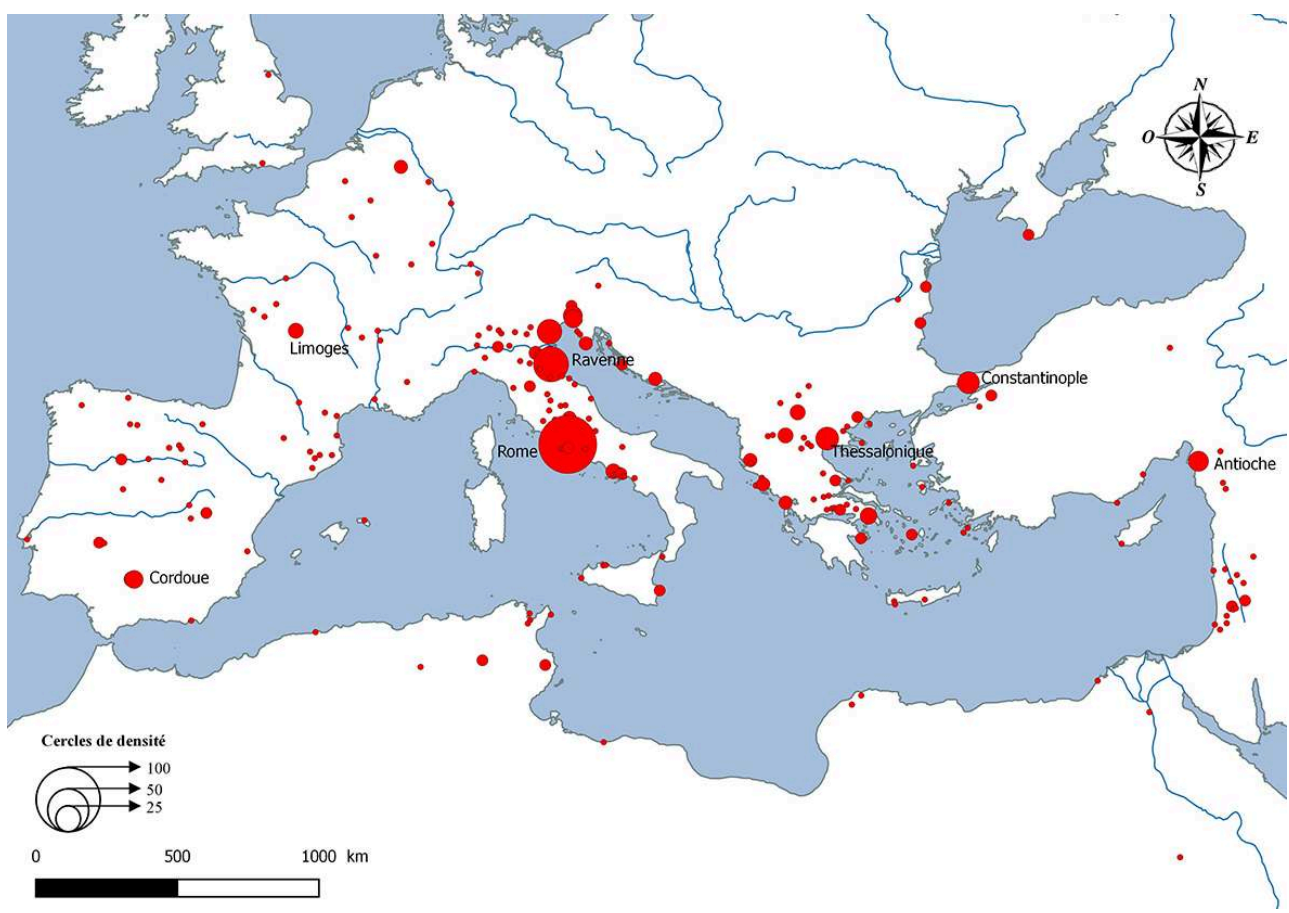

4 Concernant le phénix, il s'agit de 68 documents datés entre le $\mathrm{I}^{\mathrm{er}}$ siècle et le XIII ${ }^{\mathrm{e}}$ siècle (cf. fig. 1) et répartis dans 25 cités autour et au-delà du Bassin méditerranéen (cf. fig. 2 et fig. 5). 
Fig. 5 - Répartition et proportion des figurations du phénix, du benu et des créatures hybrides par cité concernée entre le $\|^{\mathrm{e}}$ millénaire av. J.-C. et le XIII ${ }^{\mathrm{e}}$ siècle

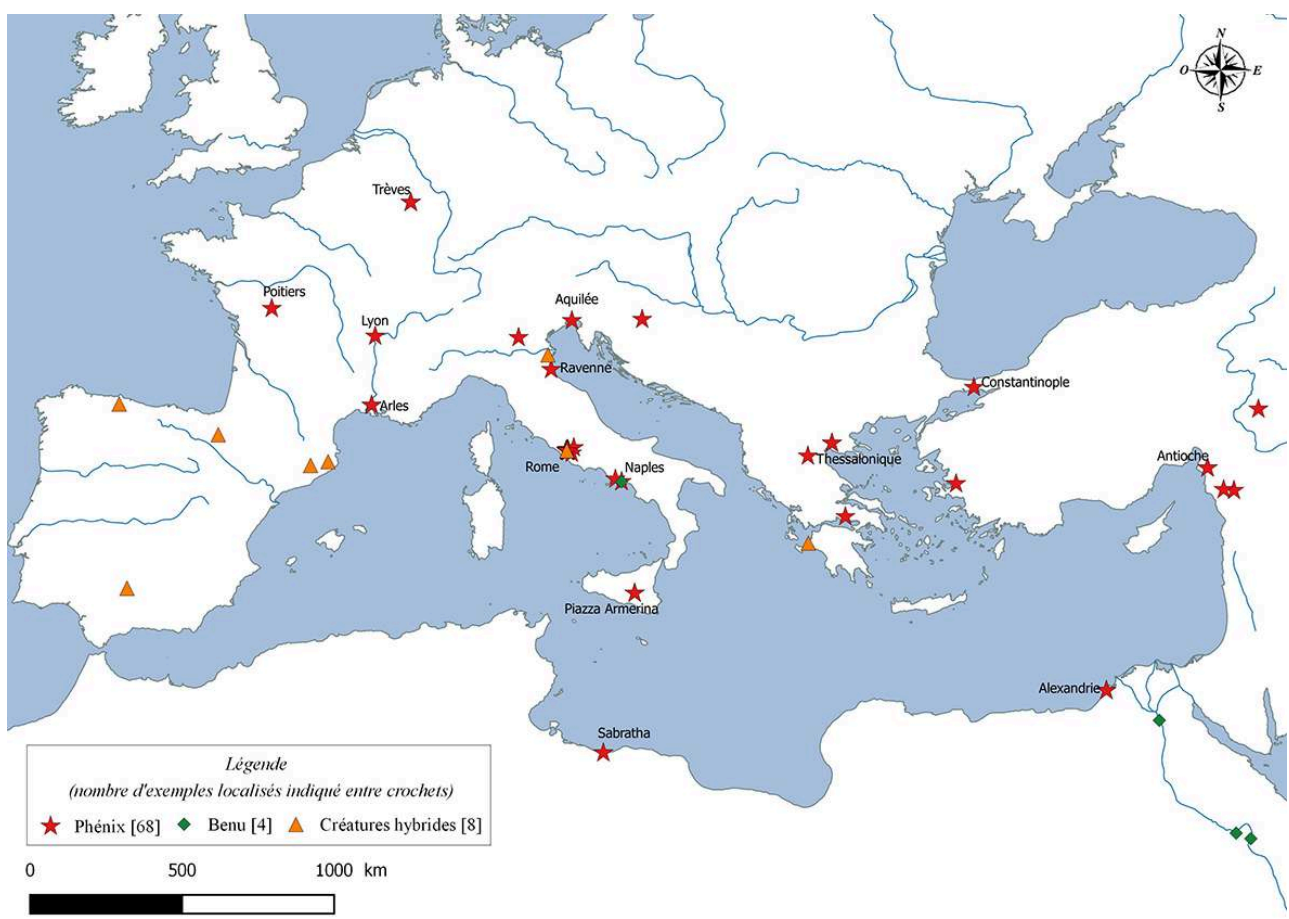

Quatre benu - l'ancêtre égyptien du phénix latin - ainsi que huit créatures hybrides, c'est-à-dire des créatures partageant certaines caractéristiques avec le paon ou le phénix, ont été ajoutées pour nourrir nos réflexions sur la composition de la figure du paon et du phénix à partir des premières mises en image connues (cf. fig. 5). La diversité des contextes, des supports utilisés et des éléments figurés en périphérie du paon et du phénix nous a conduit à concevoir une base de données informatique. La mise en série des données au moyen de cet outil fait émerger des tendances, des constantes et des variables dans l'iconographie du paon et du phénix jusqu'aux XII ${ }^{\mathrm{e}}$ $\mathrm{XIII}^{\mathrm{e}}$ siècles. Chaque document est également analysé comme un champ visuel, une composition à part entière ou bien encore comme un discours visuel complexe au sein duquel le paon et/ou le phénix s'impose comme un argument essentiel. Ces deux oiseaux entrent en écho avec d'autres éléments porteurs de sens au sein d'un ensemble structuré comparable à un mécanisme, dont ils seraient des rouages essentiels.

La mise en série des données a ouvert diverses pistes de réflexion et apporté un autre regard sur la composition de l'iconographie du paon et du phénix jusqu'aux XII ${ }^{\mathrm{e}}$ $\mathrm{XIII}^{\mathrm{e}}$ siècles. Dans les deux cas, il s'agissait de s'interroger sur les modalités visuelles de leur figuration. La position, le plumage ou bien encore les couleurs de ces oiseaux furent ainsi observées. La confrontation des documents a ainsi permis de mettre en évidence que la longue queue ocellée - traînante ou déployée en roue - du paon l'identifie comme tel dans près de $90 \%$ des cas (fig. 6). 
Fig. 6 - Répartition des paons figurés en fonction de trois critères d'identification (aigrette, queue déployée en roue, queue traînante)

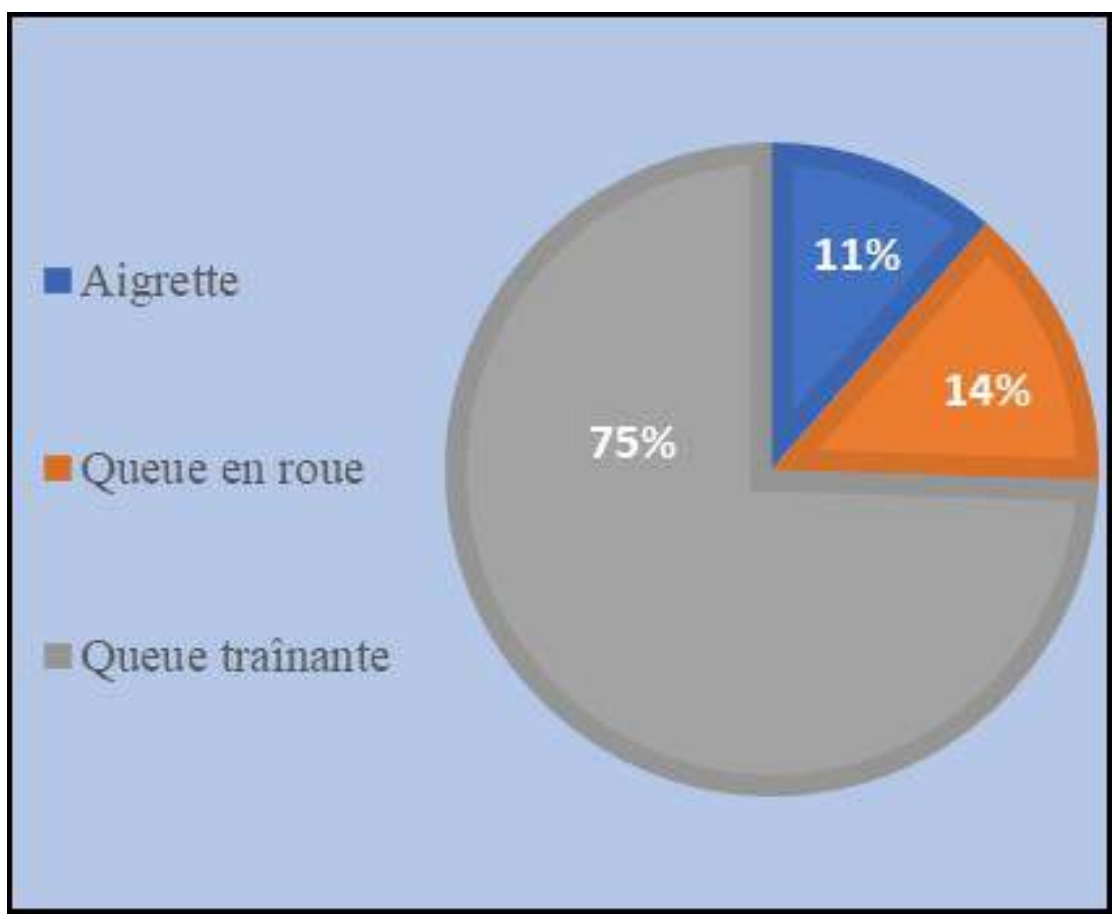

7 L'image du paon présenté de face et faisant la roue est moins répandue que celle $d u$ couple de paons vus de profil et réunis autour d'un objet (fig. 7).

Fig. 7 - Répartition des paons figurés en fonction du nombre d'oiseaux par composition (individuel, en couple, en série)

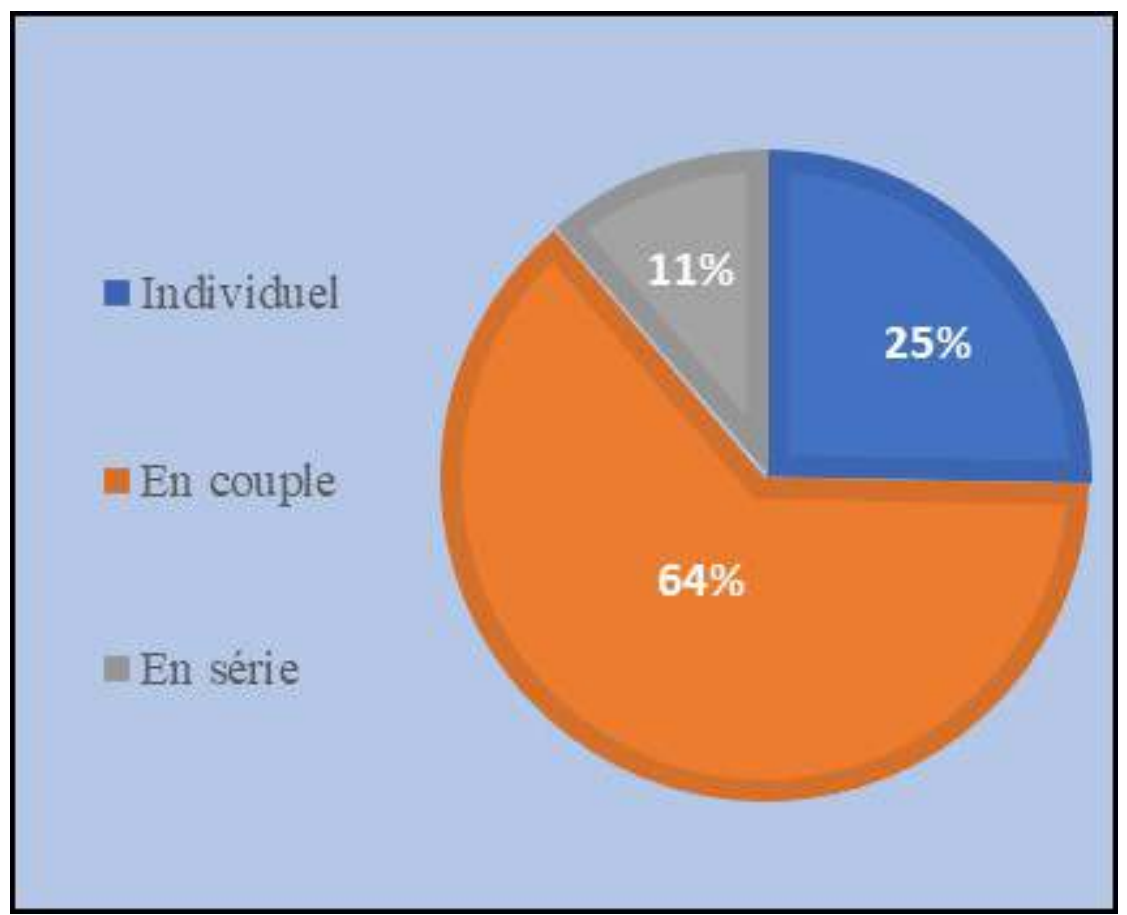

8 Concernant le phénix, sa figuration sous les traits d'un aigle au plumage flamboyant issu de la tradition hérodotéenne est assez rare jusqu'au XIII ${ }^{\mathrm{e}}$ siècle. L'oiseau légendaire 
apparaît plutôt sous la forme d'un oiseau indifférencié - sans attribut particulier - ou d'un échassier hérité du benu égyptien. L'oiseau indifférencié, l'échassier et le rapace constituent, selon nous, une souche visuelle sur laquelle sont greffés des éléments qui caractérisent le phénix et lui donnent corps dans l'imaginaire antique et médiéval (fig. 8).

Fig. 8 - Répartition des trois principaux types de figuration du phénix en fonction de sa forme de base (échassier, rapace, oiseau indifférencié)

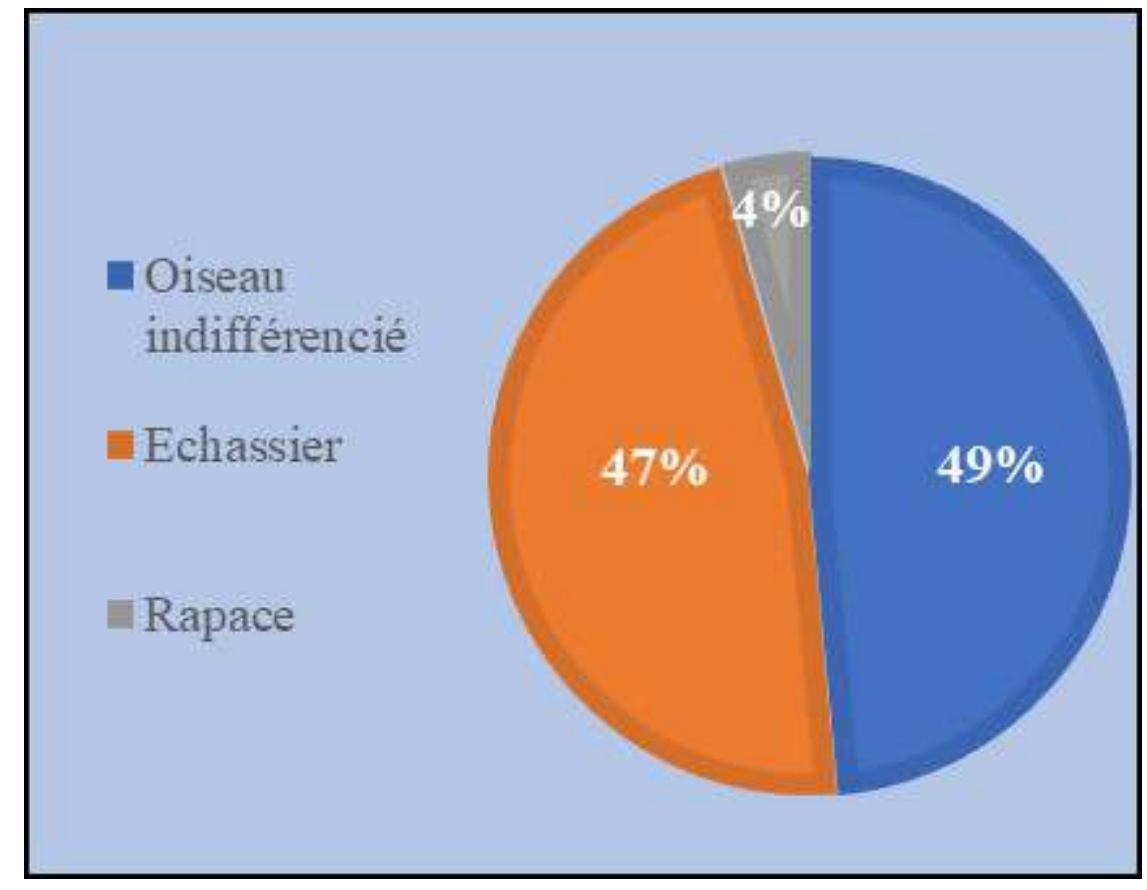

9 La palette chromatique est plus large pour le phénix que pour son ancêtre égyptien et le plumage rouge et or n'est pas systématique au vu des documents répertoriés. À partir du $\mathrm{II}^{\mathrm{e}}$ siècle, l'un des principaux attributs du phénix est le nimbe, le plus souvent radié. Le tertre, la sphère, puis dès le $\mathrm{IV}^{\mathrm{e}}$ siècle le palmier-dattier et le nid enflammé participent également à la caractérisation du phénix (fig. 9). 
Fig. 9 - Répartition des principaux attributs du phénix comme critères d'identification

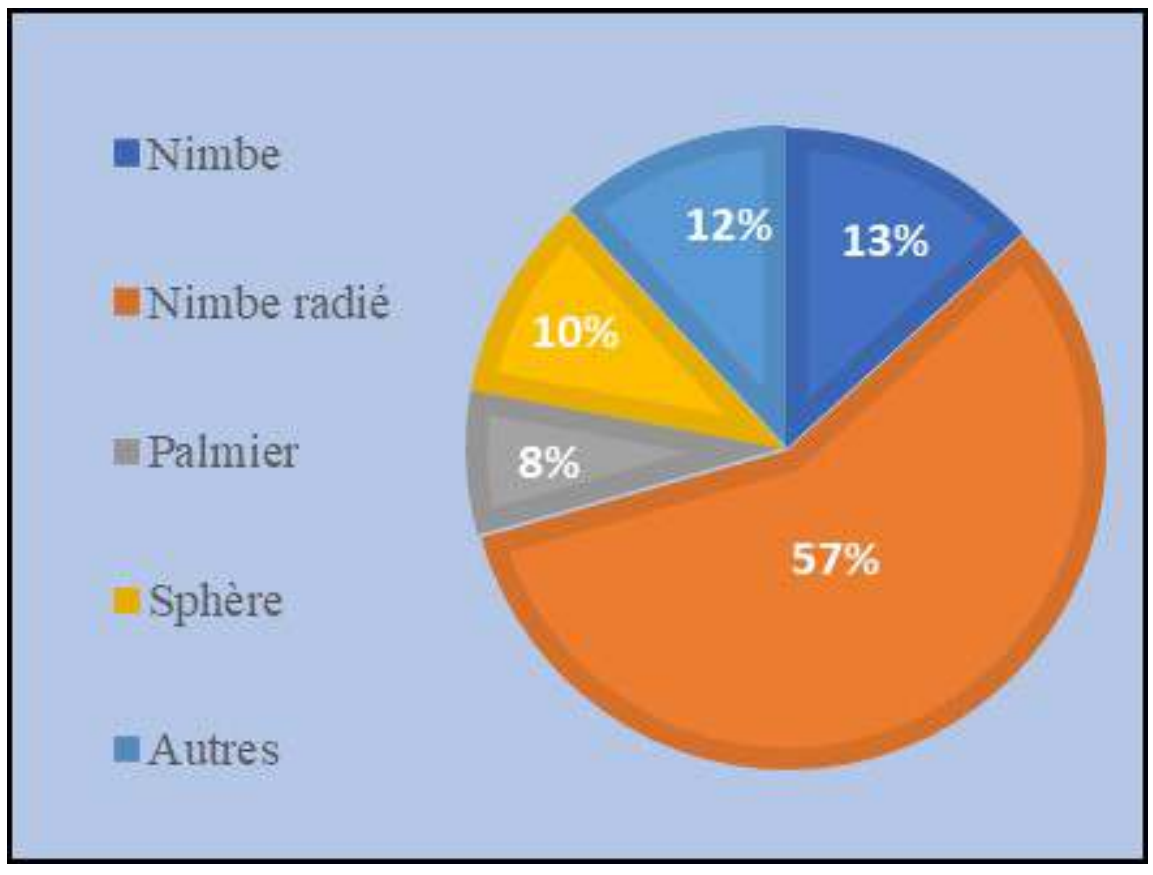

Ce dernier entretient un rapport étroit avec son présentoir, jusqu'à une certaine fusion dans le cas du palmier (phoenix). Le nimbe radié et les différents supports du phénix se cumulent pour renforcer l'impact de cet oiseau mythique lié à la cyclicité, à la renaissance et au triomphe sur la mort. Chacune des figures du paon et du phénix peut, à nos yeux, être envisagée comme une formule visuelle inscrite dans une composition, qui, elle-même, rassemble, ordonne et fait dialoguer plusieurs éléments au sein d'un ensemble structuré.

11 La deuxième partie est précédée d'une enquête portant sur les prémices littéraires et iconographiques des deux oiseaux. Cette enquête remontant aux racines antiques du paon et du phénix débute au moment de la supposée introduction du paon indien dans le Bassin méditerranéen par le roi Salomon (970-931 av. J.-C.). En croisant plusieurs ressources littéraires, nous avons démontré que le paon fut importé en Mésopotamie par voie commerciale au viII siècle av. J.-C., cet oiseau étant considéré comme un bien de valeur - au même titre que l'or, l'ivoire et les pierres précieuses -, ce dont témoigne l'ambivalence du terme hébreu "toukkiyyim », traduit dans certaines versions du Livre des Rois par "paons" ${ }^{8}$. Nous avons mis en évidence que le paon était synonyme de contrées lointaines, de même que le mythique phénix. Des liens étroits unissent les deux oiseaux également associés tous deux au thème de la renaissance, dès le $v^{e}$ siècle av. J.- $\mathrm{C}^{9}$. Le paon, dont les plumes caudales repoussent chaque année, est mis en relation avec le renouveau et devient l'attribut d'Héra entre le $\mathrm{VI}^{\mathrm{e}}$ et le $\mathrm{v}^{\mathrm{e}}$ siècle av. J.C. En outre, la dimension eschatologique du paon émerge à cette époque. C'est ainsi qu'il est mis en image sur plusieurs couronnes funéraires en Étrurie, avant de rejoindre le thiase dionysiaque entre le $\mathrm{III}^{\mathrm{e}}$ et le $\mathrm{II}^{\mathrm{e}}$ siècle av. J.-C. Le croisement de différentes ressources textuelles et visuelles nous a permis de faire apparaître que le paon était perçu comme un médiateur entre la terre et le ciel, ainsi qu'entre l'humain et le divin. De fait, le rôle de psychopompe du paon perdure dans la mise en scène de l'apothéose de l'impératrice durant les trois premiers siècles (fig. 10) ${ }^{10}$. 
Fig. 10 - Aureus commémorant l'apothéose de Julia Titi Filia (64-89), Rome, 91-92
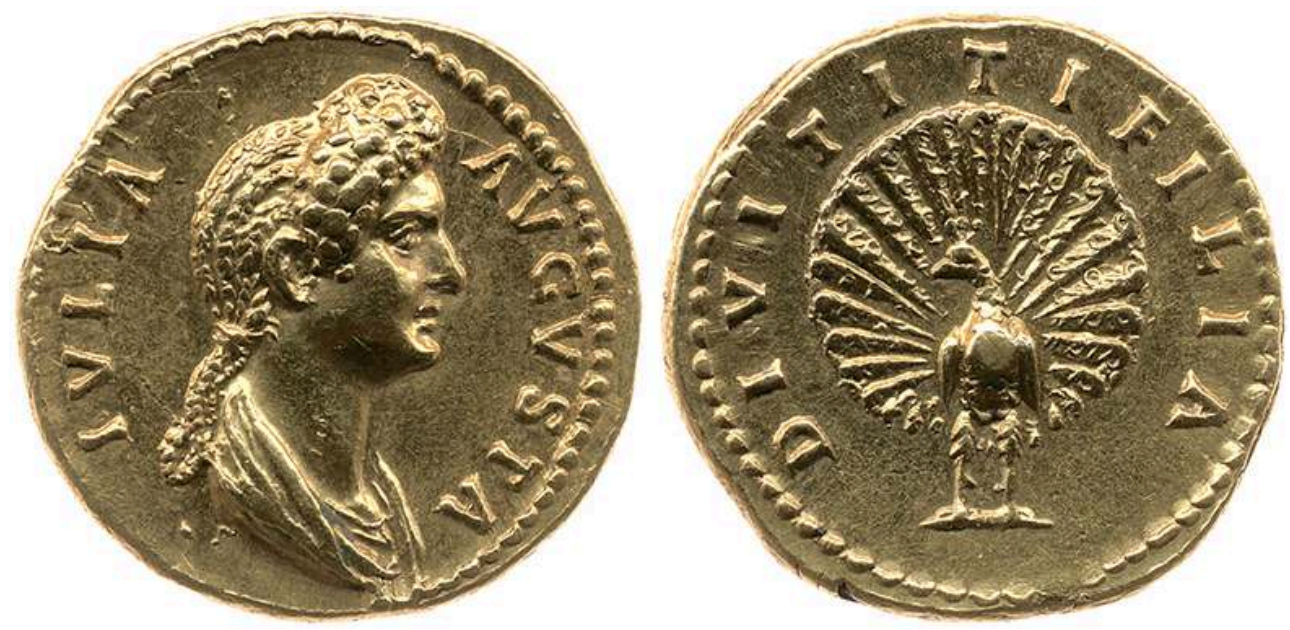

LoNDon, British Museum, inv. $n^{\circ} 1864,1128.45$, en ligne [https://www.britishmuseum.org/research/ collection_online/search.aspx?searchText=1864,1128.45]

Le benu-phénix romanisé a également été instrumentalisé par le pouvoir impérial entre le $\mathrm{II}^{\mathrm{e}}$ et le $\mathrm{IV}^{\mathrm{e}}$ siècle pour annoncer le début d'une période de stabilité politique, de prospérité et de felicitas, comme c'est le cas par exemple sur des pièces de monnaie (fig. 11).

Fig. 11 - Sur le revers, Hadrien (117-138) ou Aiôn entouré du cercle du Zodiaque présente une sphère sur laquelle trône le phénix. Aureus, Rome, 121-122

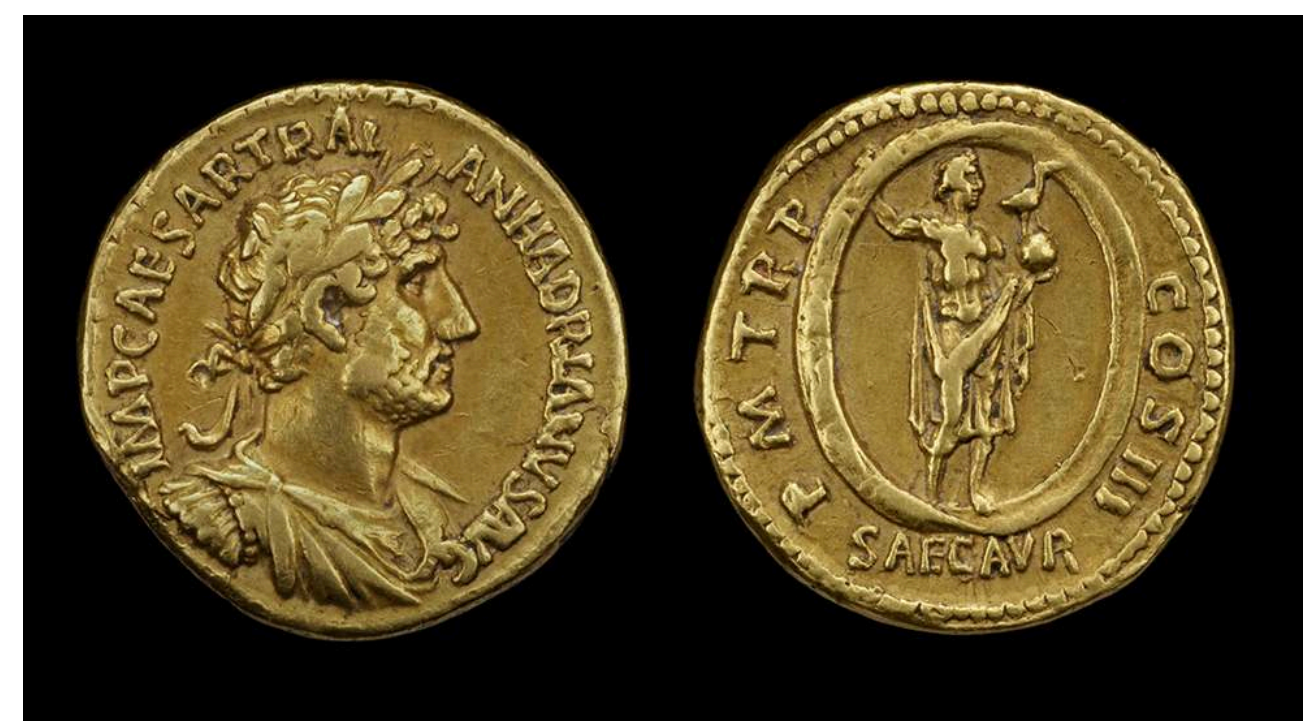

LonDon, British Museum, inv. R.8145, en ligne [https://www.britishmuseum.org/research/ collection_online/search.aspx?searchText=R.8145]

14 Cette double instrumentalisation en contexte impérial participe au processus de migration du paon et du phénix depuis la sphère funéraire vers l'édifice de culte chrétien au cours des premiers siècles, processus étudié dans la deuxième partie. En effet, l'un des axes essentiels de notre réflexion est la christianisation du paon et du phénix. Nous avons souligné que ce phénomène s'est effectué progressivement et par glissements de sens entre le $\mathrm{III}^{\mathrm{e}}$ et le $\mathrm{IV}^{\mathrm{e}}$ siècle. Associé au processus de renaissance, le 
paon est mis en rapport dans les catacombes romaines avec la purification du baptême par lequel l'individu meurt symboliquement pour mieux renaître au sein de l'Église. À la même époque, dans les catacombes de Priscille à Rome, le phénix est figuré au cœur d'un brasier ardent synonyme de renaissance, de régénération, de purification, tel un baptême par le feu avant la résurrection. L'oiseau ressuscité dans son tombeau-berceau enflammé incarne la victoire du Christ sur la mort et apporte ainsi un espoir de salut aux fidèles. La lumière de la vie éternelle portée par le phénix devient alors synonyme d'incorruptibilité, ce à quoi le paon fait également référence à partir du $\mathrm{IV}^{\mathrm{e}}$ siècle $^{11}$. À la fin $\mathrm{du} \mathrm{IV}^{\mathrm{e}}$ siècle, la christianisation du paon et du phénix atteint un niveau supérieur. Ils sont introduits dans l'espace ecclésial à Aquilée et contribuent, dès lors, au rapprochement du fidèle avec Dieu (fig. 12 et 13).

Fig. 12 - Détail d'un des paons, mosaïque de pavement, basilique alla Beligna, Aquilée, fin du IV siècle

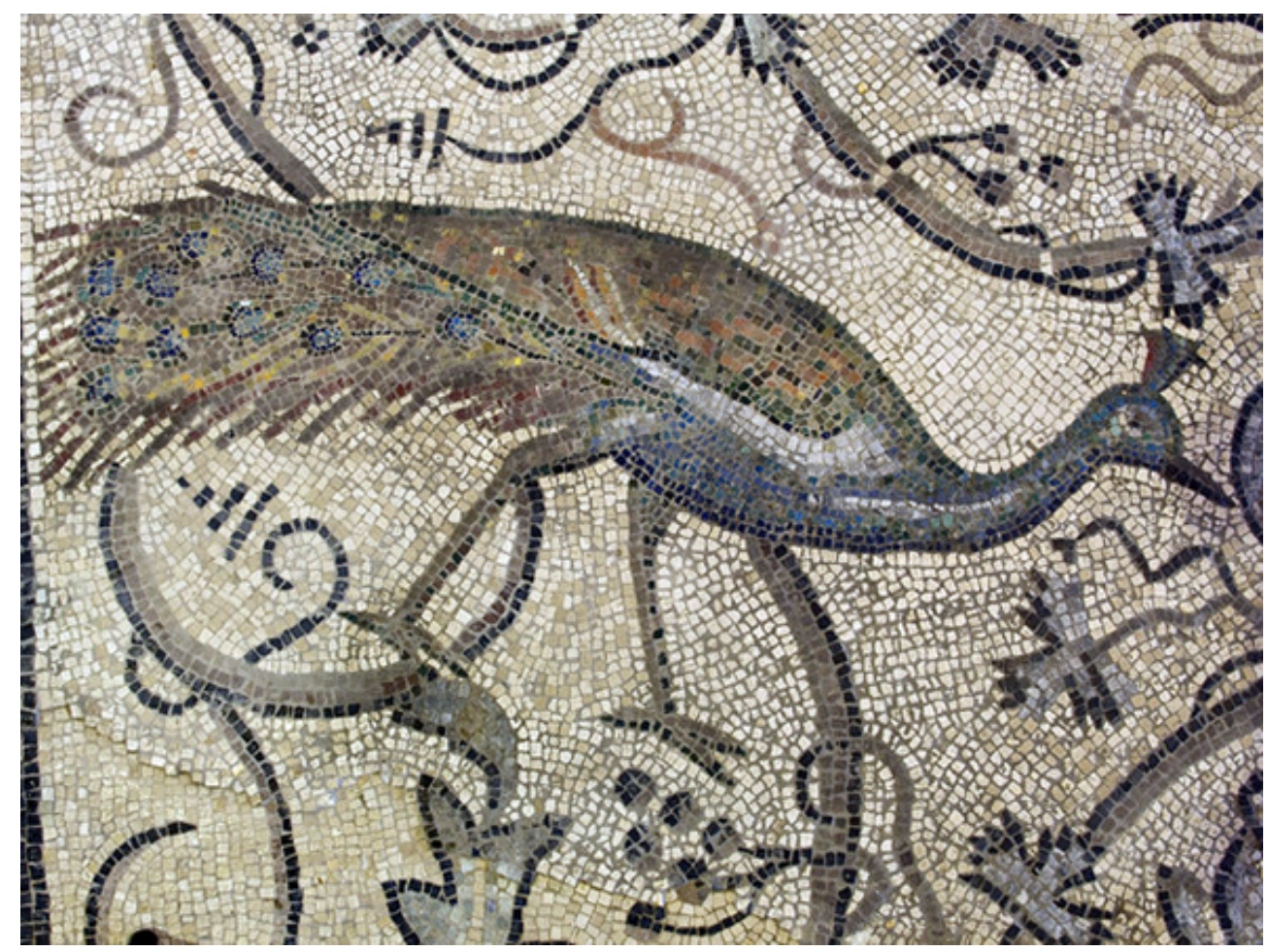

AQUILEIA, Museo archeologico nazionale, en ligne [http://www.arte.it/luogo/particolare-del-pavimento-amosaico-dell-abside-5321] 
Fig. 13 - Détail du phénix, mosaïque de pavement, basilique post-théodorienne, Aquilée, fin du IV siècle

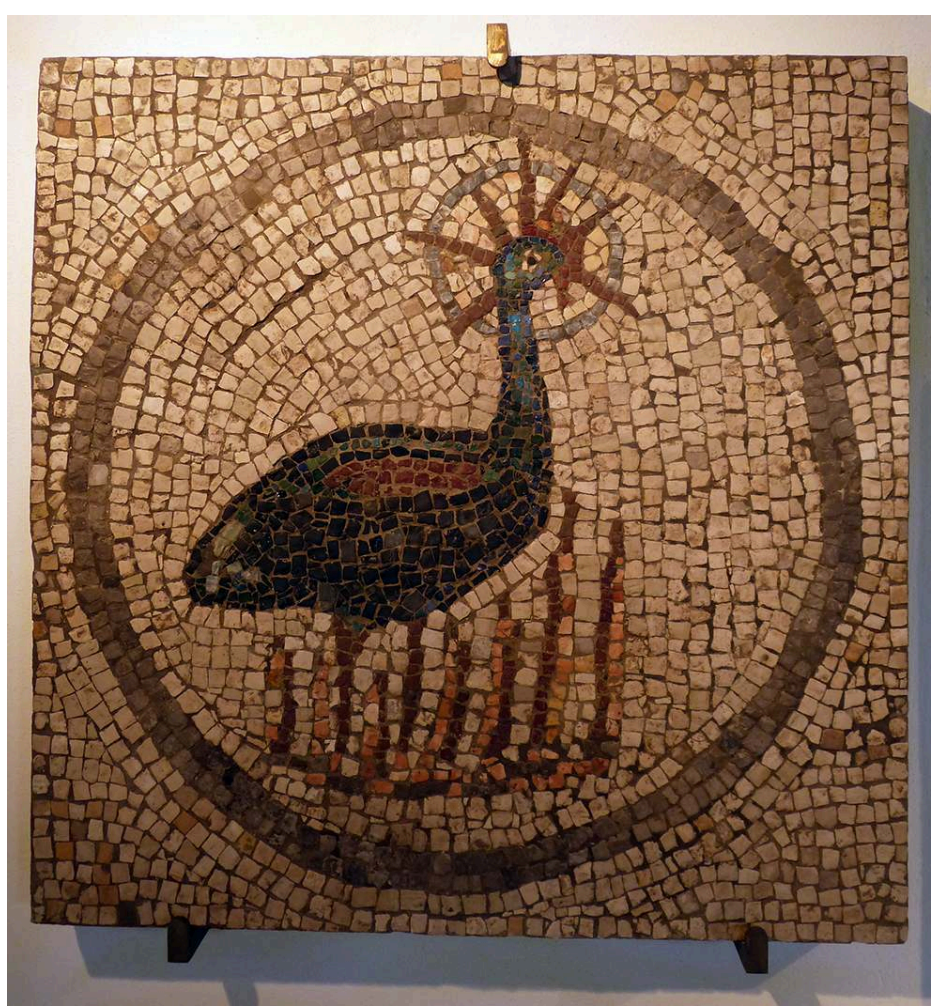

AquileiA, Museo archeologico nazionale, cl. É. Guilhem, 2014

Ce rapprochement s'intensifie au $v^{\mathrm{e}}$ siècle, de sorte que le paon et le phénix incarnent un espoir de salut comme nous avons cherché à le montrer dans une troisième partie. Notre regard s'est ainsi porté sur plusieurs décors ecclésiaux réalisés au $\mathrm{v}^{\mathrm{e}}$ siècle. L'étude parallèle de ces décors monumentaux nous a permis de mettre en lumière que les liens étroits tissés entre le paon, le phénix et le sacrement baptismal se sont resserrés. De fait, le phénix et les deux paons présentés au sommet de la coupole du baptistère San Giovanni in fonte de Naples (v. 450) contribuent à la mise en scène de l'administration du baptême, lequel participe au processus de spiritualisation de la chair de l'individu (fig. 14). 
Fig. 14 - Détail du sommet de la coupole du baptistère San Giovanni in fonte, Naples, début du ve siècle

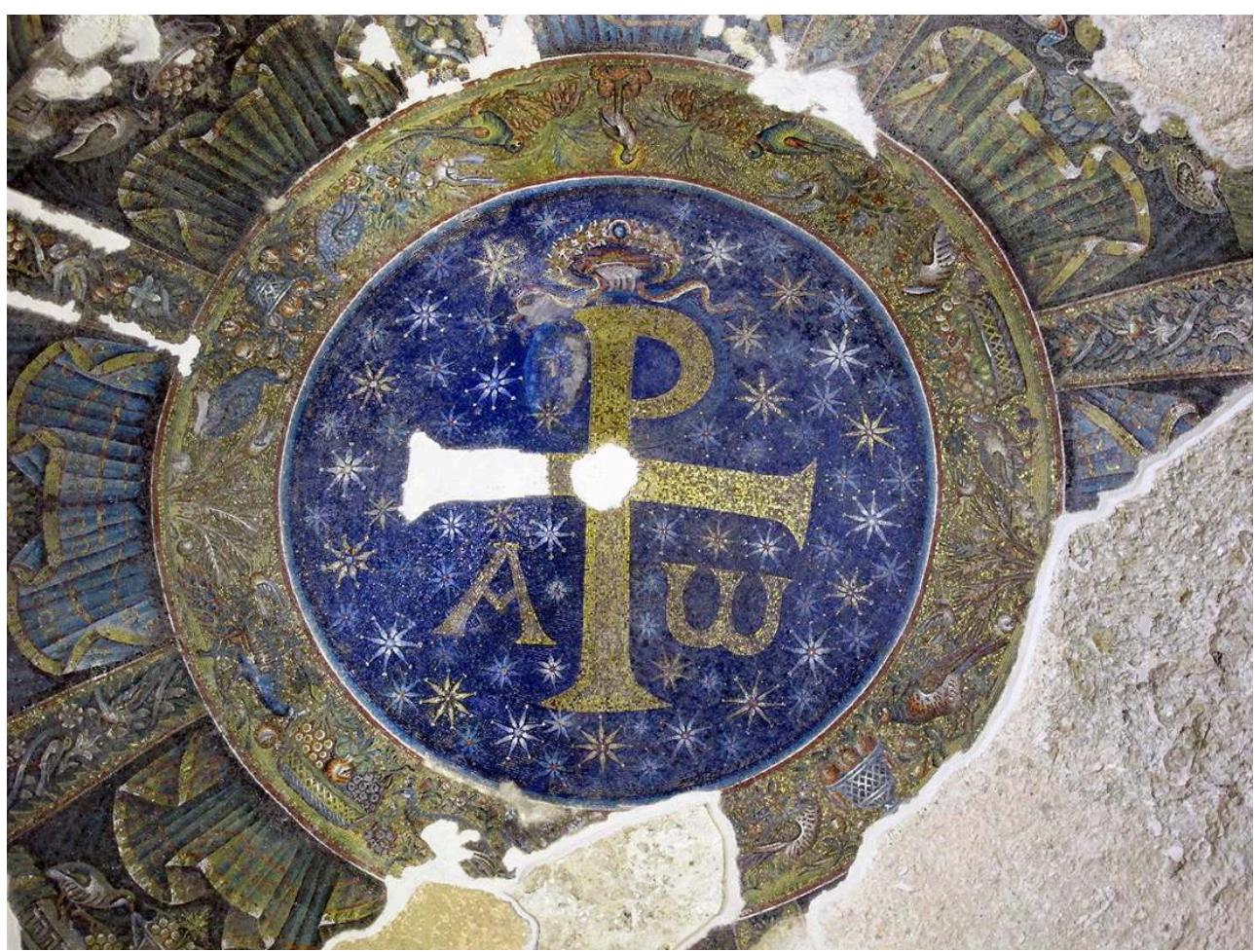

En ligne [https://commons.wikimedia.org/wiki/

File:Battistero_di_s._giovanni_in_fonte,_mosaici_del_390_ca.,_croce_monogrammatica_02.JPG]

16 Étroitement lié à la croix-trophée dont il amplifie la portée dans le décor, le phénix radieux témoigne du sacrifice du Christ et célèbre la Résurrection en apparaissant majestueusement sur un monticule, cette fois-ci paradisiaque, au centre du nouvel Éden illuminé par l'éclat de la vie éternelle. Au sein de l'escorte du phénix couronné de lumière, les paons au plumage éclatant sont réunis autour d'une corbeille de fruits traduisant l'idée d'abondance de l'Éden retrouvé. Ils protègent les fruits incorruptibles de la Croix-Arbre de Vie, commémorent le sacrifice du Christ et annoncent son triomphe sur la mort. Dans ce décor, les paons, dont la chair était réputée imputrescible, gardent l'entrée de la Jérusalem céleste et participent ainsi à l'élévation spirituelle du fidèle purifié grâce au sacrement du baptême, puis de la communion. Au sein des mosaïques du baptistère des Orthodoxes à Ravenne (v. 450), les paons rassemblés autour de la croix entrent en écho avec la renaissance de l'individu et l'invitent à communier (fig. 15). 
Fig. 15 - Détail de la face intérieure nord-est du baptistère des Orthodoxes, Ravenne, milieu du ve siècle

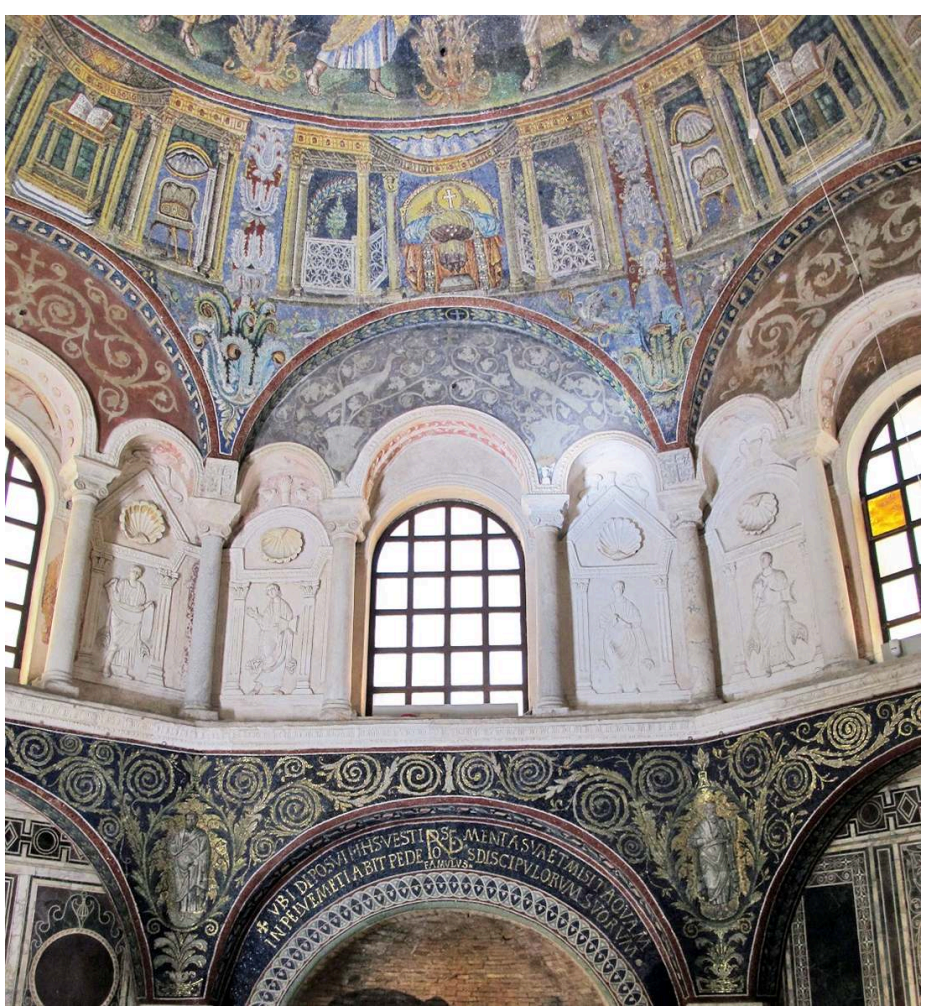

En ligne [https://commons.wikimedia.org/wiki/File:Battistero_neoniano,_int.,_stucchi_02.JPG? uselang $=\mathrm{fr}]$

L'individu est immergé dans l'axe de la scène du baptême de Jésus projeté sur la coupole, tel un pivot autour duquel sont répartis les éléments du décor, le corps étant le cardo du salut selon Tertullien (150-220) ${ }^{12}$.

Le paon apparait ainsi comme un relai des sacrements, en particulier ceux du baptême et de la communion. La quatrième partie met en exergue que le paon et le phénix sont des moyens d'introduire le fidèle dans le royaume de Dieu. C'est ce que nous avons pu observer dans différents types de décors entre le $\mathrm{VI}^{\mathrm{e}}$ et le $\mathrm{IX}^{\mathrm{e}}$ siècle, en commençant par le cas du schéma des paons réunis autour du calice ou de la croix sur plusieurs clôtures de chœur (fig. 16). 
Fig. 16 - Pluteus, vestibule, basilique Sainte-Marie-du-Transtévère, Rome, fin du vIII ${ }^{\mathrm{e}}$ siècle

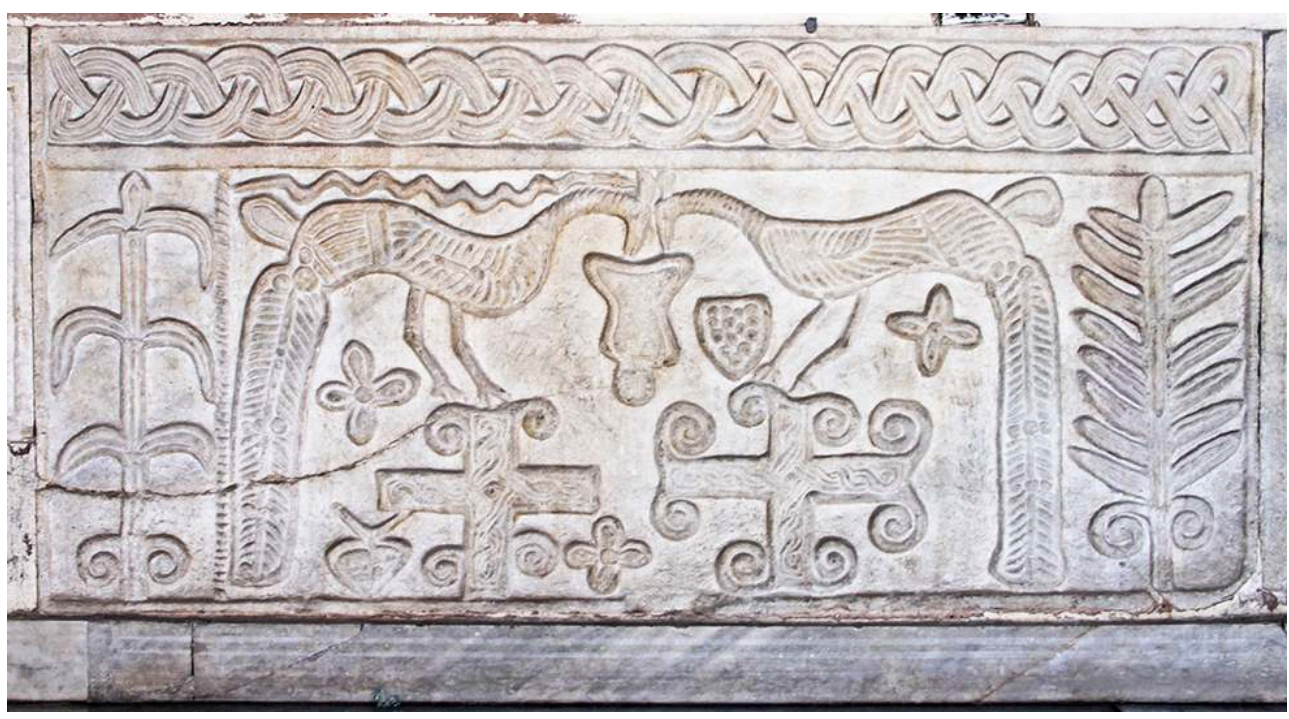

Cl. R. Demès, 2011

Les deux paons s'opposent pour faire obstacle au passage du Mal et entrent en dialogue pour favoriser la transition entre visible et invisible, entre sensible et intelligible, ainsi qu'entre charnel et spirituel. Telle une clôture ajourée, les paons affrontés sont à l'image du rapprochement progressif du fidèle avec Dieu jusqu'à l'incorporation au Christ. Les deux paons rassemblés autour du calice ou de la croix protègent le corps du Christ et incarnent la porte du salut indissociable des sacrements. Ils marquent une étape dans la progression du fidèle en gardant l'entrée du chœur et permettent aux plus méritants de franchir le seuil du royaume de Dieu. Pour ce qui est du schéma du paon faisant la roue, nous pensons qu'il faisait sens vis-à-vis du triomphe du Christ sur la mort et annonçait la résurrection des Élus à la fin des temps.

$\mathrm{Au}$ cours de la même période, le phénix est quant à lui étroitement lié aux réalisations papales romaines. Il a ainsi été question d'étudier la composition de trois décors absidaux empreints de la présence conjointe du phénix, du Christ et du pape à Rome, entre le $\mathrm{VI}^{\mathrm{e}}$ et le $\mathrm{IX}^{\mathrm{e}}$ siècle. Dans le décor absidal de la basilique Saints-Cosme-et-Damien, le pape Félix IV (526-530) cherche à nouer des liens de plus en plus étroits avec les martyrs romains ainsi qu'avec le Christ et le phénix dont le corps glorieux évoque la Résurrection (fig. 17). 
Fig. 17 - Détail de la conque absidale de la basilique Saints-Cosme-et-Damien, Rome, 526-530, état actuel

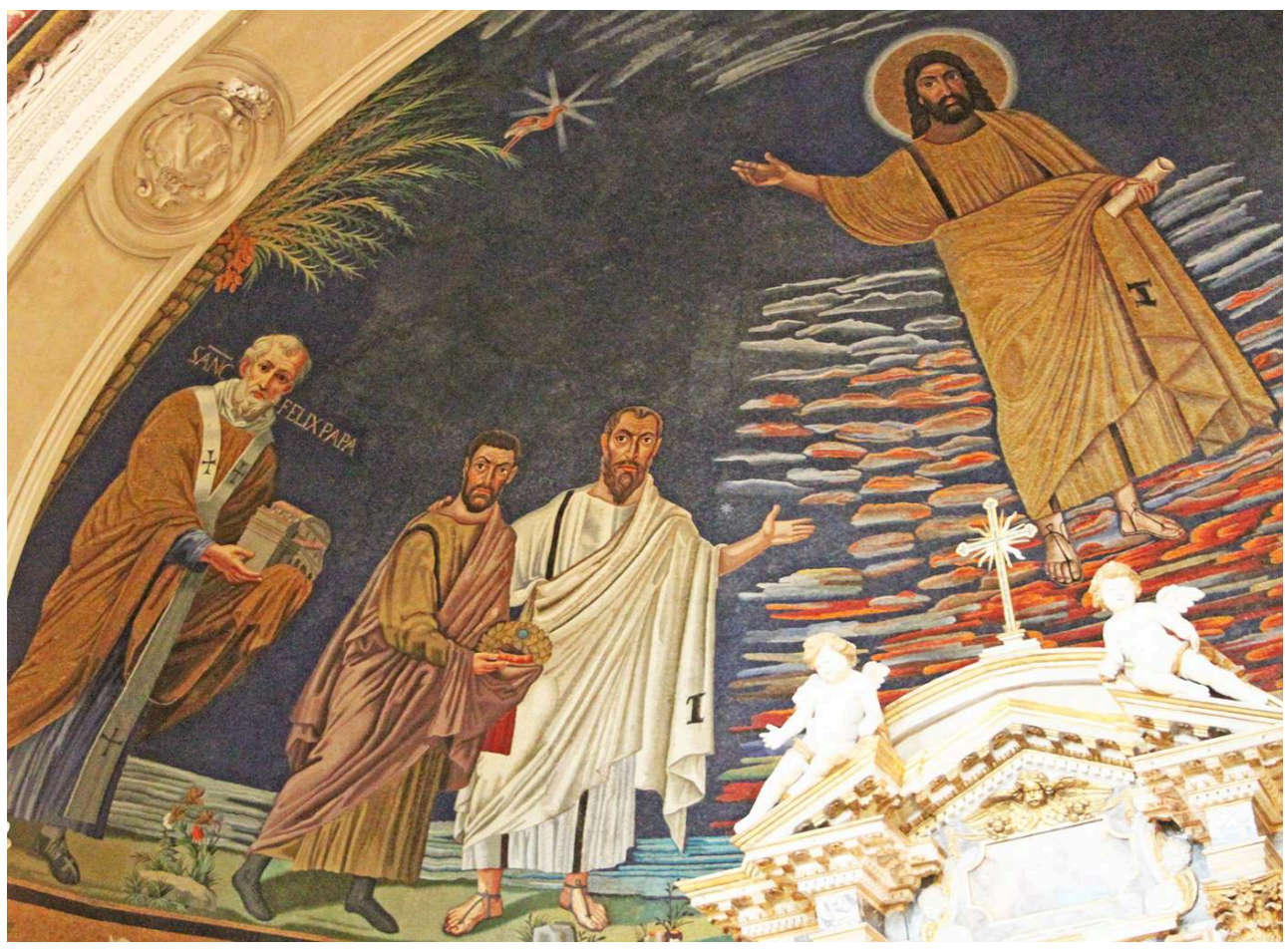

Cl. R. Demès, 2011

21 Concernant la mise en regard du paon et du phénix dans le décor absidal de SainteAgnès-hors-les-Murs (625-638), nous pensons qu'il s'agit d'une manière de révéler un autre point de contact essentiel entre les deux oiseaux (fig. 18).

Fig. 18 - Vue d'ensemble du décor absidal de la basilique Sainte-Agnès-hors-les-Murs, Rome, 625-638, état actuel

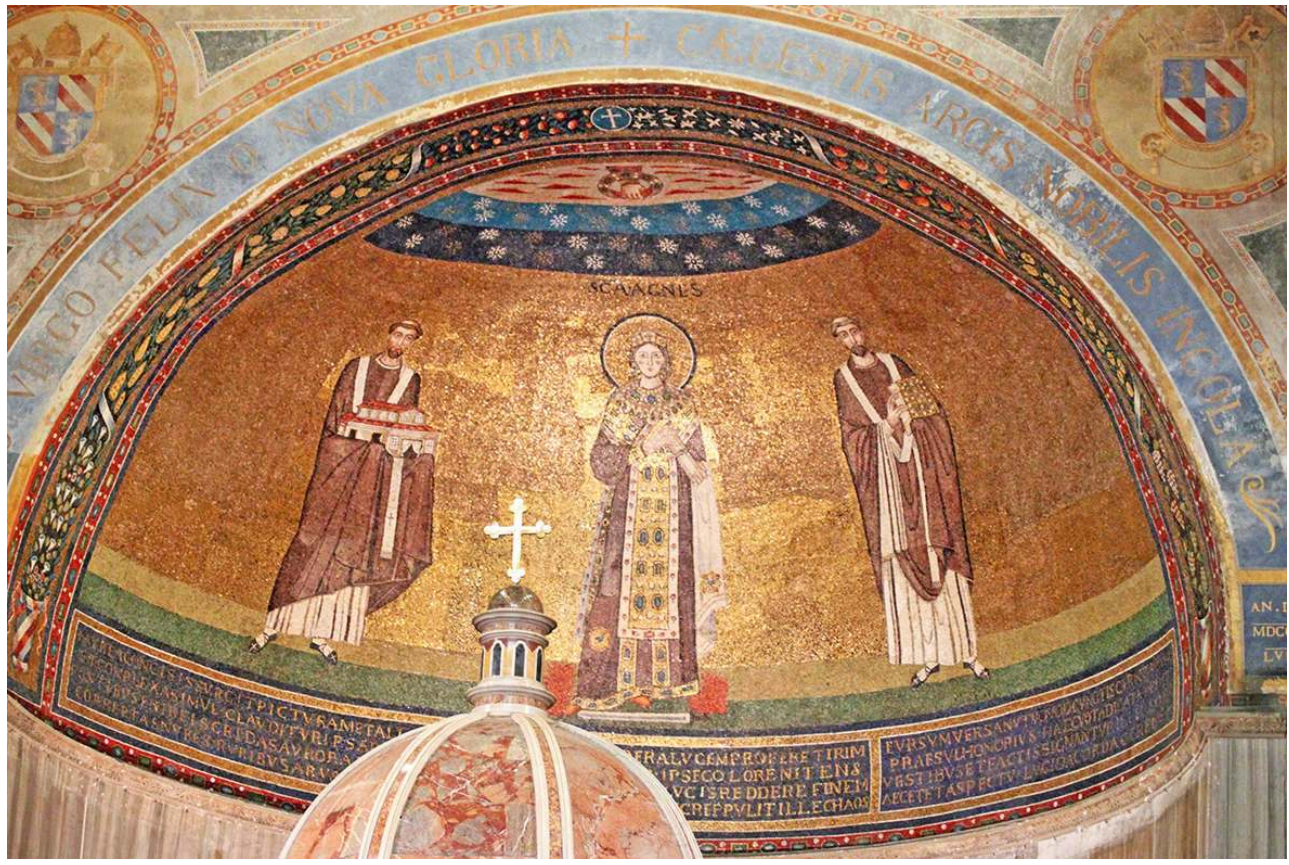

Cl. R. Demès, 2011 

précisément dans l'axe de la martyre romaine, dont la tunique est marquée par la figure du phénix arborant un plumage bleu. En outre, on retrouve un paon brodé sur le tissu blanc à liseré doré que sainte Agnès porte sur l'avant-bras gauche. Cet exemple cristallise la proximité sémantique de ces deux oiseaux. Ils interagissent, se font écho, jusqu'à se confondre au sein d'un décor dans lequel le thème de la lumière est omniprésent. Le paon-phénix associé à la pourpre renforce les liens tissés entre les deux oiseaux, ainsi baptisés dans le sang unique des martyrs et de l'Agneau, et revêtus d'une même lumière, celle de la foi et de la vie éternelle. Deux siècles plus tard, dans le décor de Sainte-Praxède, le pape Pascal $\mathrm{I}^{\mathrm{er}}$ (817-824) affiche sa volonté de faire corps avec les martyrs, avec le phénix, ainsi qu'avec le Christ en se servant d'un code chromatique particulier, alliant le bleu et le blanc (fig. 19).

Fig. 19 - Détail du décor absidal de la basilique Sainte-Praxède, Rome, 817-818, état actuel

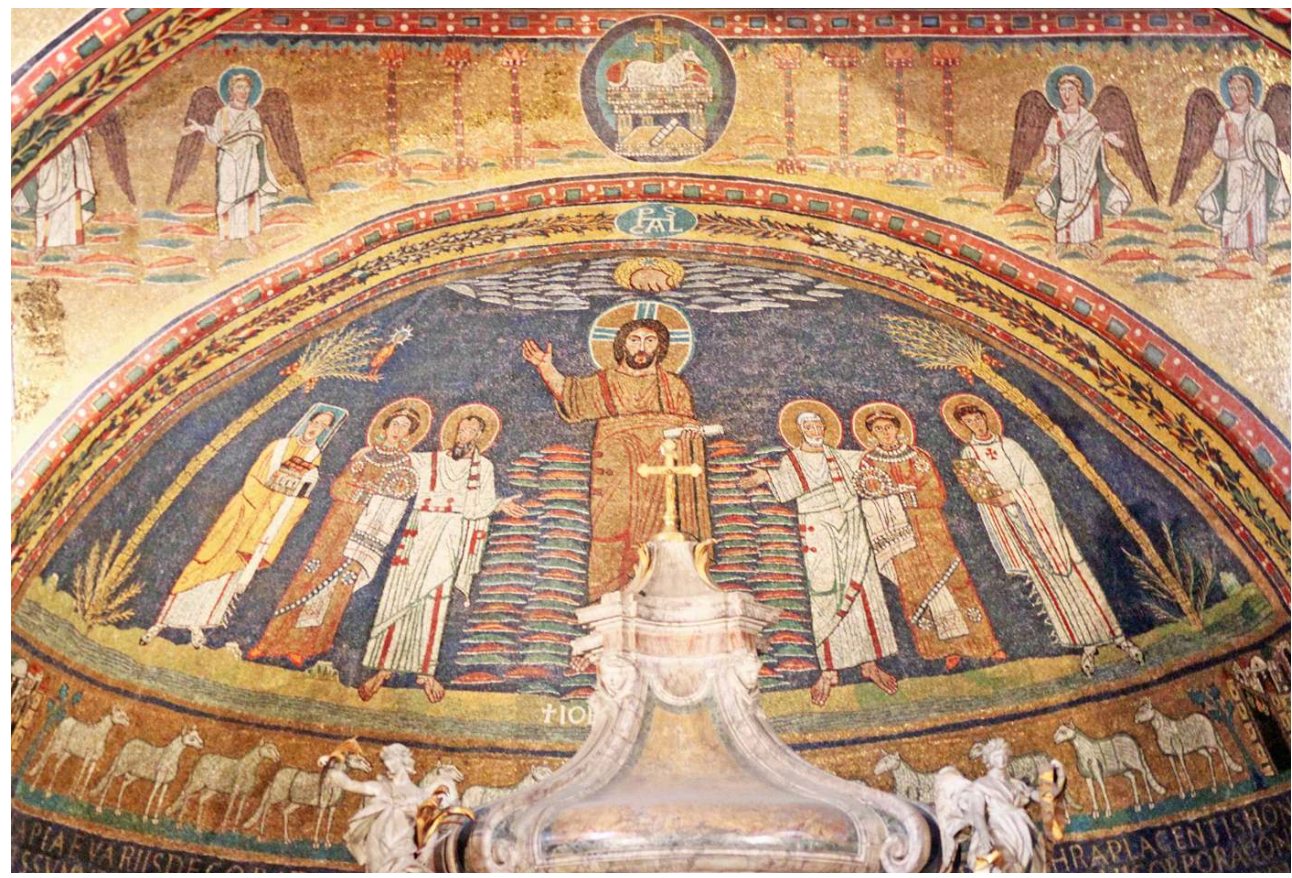

Cl. R. Demès, 2011

Introduit dans le Royaume de Dieu, le pape dédicant se place sous la protection du phénix et affirme son statut de souverain pontife. Trônant sur le palmier transformé en Arbre de Vie, le phénix, à la fois exemplum et témoin de la Résurrection, contemple Dieu sans intermédiaire. Il rayonne dans le nouvel Éden et diffuse un espoir de salut. Ainsi, l'éclat du nimbe radié de l'avis unica s'est propagé jusqu'à mettre en lumière le corps glorieux du phénix assimilé au Christ et à annoncer le rayonnement perpétuel du corps spirituel incorruptible promis aux Élus.

Au terme de notre parcours et en guise d'ouverture, nous avons cherché à montrer que l'iconographie du paon prend ensuite un nouveau souffle. De fait, le décor absidal de la basilique Saint-Clément (1118) à Rome nous a permis d'observer les différentes facettes de la signification du paon qui évolue à partir du XII ${ }^{e}$ siècle. Au sein de ce décor, les paons témoins de la Crucifixion gardent l'accès au fons vitae et s'imposent comme des figures de médiation entre le terrestre et le céleste (fig. 20). 
Fig. 20 - Vue d'ensemble du décor absidal de la basilique Saint-Clément, Rome, 1118, état actuel

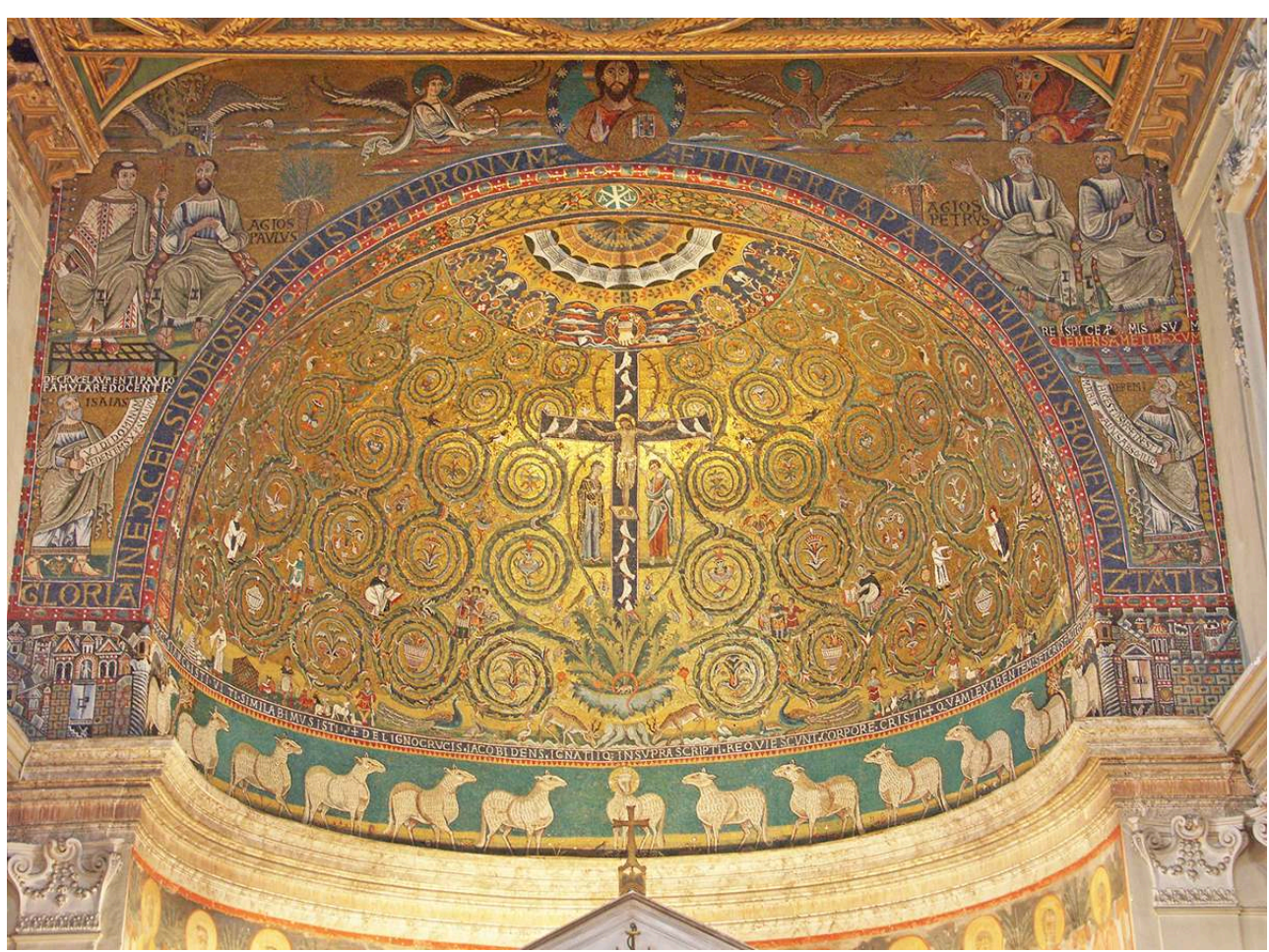

En ligne [https://commons.wikimedia.org/wiki/File:Rom,_Basilika_San_Clemente,_Apsis_1.jpg? uselang $=\mathrm{fr}]$

Dans ce même décor, le paon faisant la roue est à l'image du renouveau permis par le sacrifice du Christ et de la résurrection promise aux Élus. Par ailleurs, l'éclat de ses couleurs vives reflète celui des multiples vertus dont l'homme peut orner son âme pour se rapprocher de Dieu tout en prenant garde au piège des apparences. Le paon incarne alors un modèle de piété et d'humilité et, dans le même temps, il devient un contre exemple renvoyant au laïc paré de vertus ostentatoires et au clerc assoiffé de louanges ou de vaine gloire. Au XII siècle, le paon commence à être tiraillé entre différentes valeurs, avant de pencher plutôt vers la fierté, l'orgueil et la vanité.

Les réflexions menées au cours de ce travail pourraient être prolongées de plusieurs manières. Entre le $\mathrm{x}^{\mathrm{e}}$ et le $\mathrm{XII}^{\mathrm{e}}$ siècle, le paon a été figuré sur différents supports, tels que des coffrets en ivoire hispano-italiens, des manuscrits et des chapiteaux produits en Espace actuelle, en France et en Italie. Notre thèse a mis en lumière certains de ces documents, mais une étude systématique et approfondie de l'ensemble de ces témoignages reste à mener. Ces derniers fournissent un aperçu de différents phénomènes de réappropriation de la figure du paon. Celle-ci se diffuse d'une rive à l'autre du Bassin méditerranéen jusqu'à apparaître, par exemple, sur des coffrets en ivoire, autrement dit des objets circulant entre les cours d'Andalousie, de Sicile et du sud de l'Italie. Enfin, la présence conjointe du paon et du phénix au sein du décor absidal de la basilique Saint-Jean-du-Latran (1291) ouvre de nombreuses pistes de réflexion sur le renouveau d'une iconographie au cœur d'un discours ecclésiologique dans la Rome de la fin du XIII ${ }^{\mathrm{e}}$ siècle.

Reçu : 03 septembre 2018 - Accepté : 17 décembre 2018 


\section{NOTES}

1. Apollinaire, CEuvres poétiques, Paris, 1956 (Bibliothèque de la Pléiade, 121), Le bestiaire, «Le paon ".

2. R. DEMÈs, Le thème iconographique du paon entre les $I^{e}-V^{e}$ siècles et le XII siècle à Rome et dans l'espace urbain des grandes basiliques romaines, mémoire de Master 1 sous la direction de Daniel Russo, université de Bourgogne, 2009 ; ID., Le thème iconographique du paon entre les I $V^{e}$-Ve siècles et le $\mathrm{XII}$ siècle à Rome, Ravenne et dans l'espace italo-lombard, mémoire de Master 2 sous la direction de Daniel Russo, université de Bourgogne, 2010.

3. L'enseigne peinte de la taverne ou caupona d'Euxinus à Pompéi ( $\mathrm{I}^{\mathrm{er}}$ siècle) est la première figuration du phénix en tant que tel et la plus ancienne figuration du paon et du phénix côte à côte.

4. Cette thèse a été soutenue devant un jury composé de Claire sotinel (rapporteur), Stéphane Ratti (rapporteur), François Bougard, Simone Piazza et de Daniel Russo (directeur de thèse). Nous tenons à réitérer ici nos plus vifs remerciements aux membres de notre jury de thèse ainsi qu'à exprimer notre sincère reconnaissance à notre directeur de thèse.

5. Cette ouverture à un horizon interdisciplinaire a largement été nourrie par les riches discussions menées durant différents séminaires, ateliers et journées d'études organisés par Eliana Magnani et Daniel Russo.

6. R. VAN DEN BROEK, The Myth of the Phoenix according to Classical and Early Christian Traditions, thèse, Theological Faculty of the University of Utrecht, 1971, trad. I. SEEGER, Leiden, 1972 (Études préliminaires aux religions orientales dans l'Empire romain, 24).

7. H. LOTHER, Der Pfau in der altchristlichen Kunst : eine Studie über das Verhältnis von Ornament und Symbol, Leipzig, 1929.

8. 1 Rois 10,$22 ; 2$ Chroniques $9,21$.

9. Roelof van den Broek a relevé les auteurs qui ont comparé, voire mis en concurrence, ces deux oiseaux associés à un certain exotisme, cf. R. VAN DEN BROEK, The Myth of the Phoenix..., op. cit., p. 251-253.

10. L'aureus émis à Rome entre 91 et 92 commémore l'apothéose de la divine Julia Titi Filia (64-89) prononcée par le Sénat en 90 . Il s'agit de la première association officielle du paon à l'impératrice, elle-même associée à Junon.

11. Augustin, La Cité de Dieu, Livres XVIII à XXII, trad. L. MOREAU, éd. J.-C. ESLIN, Paris, 1994, XXI, 4.

12. TERTULLIEN, La résurrection des morts, éd. et trad. A. JAUBERT, Paris, 2014, VIII, 2.

\section{AUTEUR}

\section{RAPHAËL DEMÈS}

Université de Bourgogne Franche-Comté, membre associé du Centre d'études supérieures de civilisation médiévale, université de Poitiers 